\title{
A practical application of sensory and rheological measurement in the development of fish pâté quality attributes
}

\author{
Jasmina Ranilović1, Josip Bebek ${ }^{1 *}$, Helena Tomić-Obrdalj ${ }^{1}$, Davorka Gajari' ${ }^{1}$, Tanja Cvetković1
}

${ }^{1}$ Podravka d.d., Research and development, Ante Starčevića 32, 48000 Koprivnica, Hrvatska

*Corresponding author: josip.bebek@podravka.hr

\begin{abstract}
The flavor and texture of fish paté are the most important attributes for consumers. The aim of the study was to analyze and compare commercial fish pâté with a laboratory prototype by combining sensory and rheological measurements. Quantitative Descriptive Analysis and Texture profile were established by expert sensory panelists, while the texture was additionally examined through rheological measurement. The results show a statistically significant difference between samples in relation to four flavor characteristics (color, fish odor, flavor saltiness, $p<0.05$ ) and five texture characteristics (surface, plasticity, spreadability, density, graininess, $p<0.05$ ). Regarding texture profile, the commercial fish pâté showed firmer density, and spreadability than does the laboratory prototype. Sensory and rheological data for both samples were highly positively correlated. Although the laboratory prototype has reached a certain level of desirable characteristics of fish pate (color, taste, spices) the acceptability of the observed differences in texture should be examined on a representative sample of consumers.
\end{abstract}

Keywords: fish pâté, sensory analysis, rheology, product development

\section{Introduction}

The global pâté market size was estimated at 1.1 billion USD in 2018, and it is expected to reach a CAGR (Compound Annual Growth Rate) of $1.3 \%$ from 2019 to 2025 (Grand View Research, 2019). Market growth is associated with a change in consumer preferences for food, higher consumption of processed food, acceptance of Western diet, and the growth of the hospitality industry that promotes worldwide cuisines. Furthermore, pâté is popular due to its convenience (ready-to-eat), which fits with today's snacking culture (Engelen and de Wijk, 2012). Europe is the largest regional pâté market with very high consumption, especially in France, where $68 \%$ of people consume pâté at least once per month. While pâté was originally made from chicken liver, many versions exist today, e.g. beef, meat, fish, pork and vegetarian pâté all very popular among consumers. A healthy diet includes high quality proteins that contain all essential amino acids, essential fatty acids, vitamins and minerals, and fish as a rich source of these nutrients. In cases where fish consumption is low, even small quantities of consumed fish can have a significant positive nutritional impact on diet (Luckett et al., 2014; Adhikari et al., 2003; Breuil and Meullenet, 2001). In comparison with meat pâté, fish pâté usually contains $20 \%$ more protein and could be beneficial in improving the diet of people who mainly avoid fish due to its strong flavor.

However, consumer behavior is a complex process, uniting numerous personal and social factors and psychological processes that describe it (Kesić, 1999). The learning process is one psychological process that lasts throughout life and accumulates everything previously learned as represented by memory. Mojet and Köstner (2002) examined the impact of incidental learning on memory related to the texture and/or flavor of biscuits, breakfast drinks, and meat pâtés. The results showed that incidentally learned food characteristics are remembered to a certain level in memory and, in most cases, women remembered them better than men did. The authors pointed out that people pay more attention to the differences between their memory and the actual food, than to its characteristics (Mojet and Köstner, 2002). Wendin and authors showed in their study that the combination of sensory and rheological measurements colud support the objective definition of food texture important in classification of texture profile foods and fluids for patients suffering from chewing problems and swallowing disorders common among elderly people (Wendin et al., 2010).

Because there is no specification for a pâte-type of product in EU regulations, food producers ultimately rely upon consumer attitudes and expectations in relation with food specific for a market and/or region (Ranilović et al., 2009). The usual fish pâté recipe in the so-called Adria region (Slovenia, Croatia, Serbia, Bosnia and Herzegovina, and North Macedonia) consists of specific fish species, vegetable fats, water, proteins, salts and spices adapted to the consumer's specific taste. Moreover, it is produced under specific production technology. The quantities of fish species and other ingredients and the production method affects the consistency of the pâté, its nutritional value (Okuskhanova et al., 2018), and the labeling of the product (pâté or spread). Consequently, in the recipe development phase, attributes related to the direct quality of a pâté-type product (flavor, color, appearance, texture, etc.) are usually compared with competitors in the market. Assuming that, for consumers, the leading fish pâte in a category practically exists as the "golden" standard, meaning that all its organoleptic attributes must be analyzed very carefully. Since, in previously published papers, the combination of sensory and rheological measurements was mainly applied to quality testing on meat pâtés, our intention was to show the practical application of these methods in the design of fish pâté as a new future product on the market. Therefore, the aim of this study was to apply sensory and rheological measurements for a comparison of a fish pâté laboratory prototype with the commercial fish pâté highly valued by consumers.

\section{Materials and methods}

In this study, two samples of fish pâtés were used for sensory and rheological analysis: One sample was a commercial fish pâté acquired from a local supermarket, while the other sample was a canned internal laboratory fish pâté prototype. 


\section{Sensory analysis}

The objective of sensory analysis was twofold, first to obtain an overall descriptive sensory profile and second to focus on the texture of the products. The expert panel for evaluation was comprised of 10 women employed in the food industry, with an average age of 45 "years trained according to HR EN ISO 8586-1, 2012. Prior to analysis, the panel had two training sessions, 45 minutes per session, to generate and describe the product attributes, through consensus according to Wendin et al., 2010; HR EN ISO 11036, 1990; HR EN ISO 13299, 2016; Nielsen et al., 2020; Lawless and Heymann, 2010. The expert panel developed a lexicon of seven sensory attributes for Quantitative Descriptive Analysis $\mathrm{QDA}^{\circledR}$ and six attributes for Texture profile, selected attributes and definitions that are presented in Table 1 according to HR EN ISO ISO 5492, 1999. QDA ${ }^{\circledR}$ and Texture profile were carried out in two replicates by using a $150-\mathrm{mm}$ continuous scale anchored by low intensity at $10 \mathrm{~mm}$, on the left, and by high intensity at $140 \mathrm{~mm}$. Samples in the amount of $50 \mathrm{~g}$ were served on white ceramic plates coded by three-digit number, at room temperature $\left(25^{\circ} \mathrm{C}\right)$. Samples were presented monadically to judges in a random order. All analyses were conducted at a food industry in-house sensory laboratory.

Table 1. Attributes and descriptions used in sensory analysis.

\begin{tabular}{|c|c|}
\hline Attributes & Description \\
\hline Color & Attribute inducing colour sensation. \\
\hline Odor of seasonings & $\begin{array}{l}\text { The overall intensity of volatile compounds } \\
\text { of seasonings analyzed ortonasaly. }\end{array}$ \\
\hline Fish odor & $\begin{array}{l}\text { The volatile compounds associated with } \\
\text { fish analyzed ortonasaly. }\end{array}$ \\
\hline Seasonings & $\begin{array}{l}\text { Aromas associated with seasonings } \\
\text { perceptible in mouth and retronasaly. }\end{array}$ \\
\hline Fish flavor & $\begin{array}{l}\text { Aromas associated with fish perceptible in } \\
\text { mouth and retronasaly. }\end{array}$ \\
\hline Saltiness & Taste of sodium chloride. \\
\hline Aftertaste & $\begin{array}{l}\text { Pleasantness rating for residual taste after } \\
\text { elimination of product from oral cavity. }\end{array}$ \\
\hline Smoothness of surface & $\begin{array}{l}\text { Appearance and smoothness of surface } \\
\text { analyzed visually. }\end{array}$ \\
\hline Plasticity & $\begin{array}{l}\text { Mechanical texture attribute related to } \\
\text { resistance to deformation by using knife }\end{array}$ \\
\hline Spreadability & $\begin{array}{l}\text { Mechanical texture attribute related to force } \\
\text { required to remove material from surface of } \\
\text { slice of bread by using knife. }\end{array}$ \\
\hline Density & $\begin{array}{l}\text { Mechanical textural attribute relating to } \\
\text { the force required to deform or penetrate a } \\
\text { product by using knife. }\end{array}$ \\
\hline Graininess & $\begin{array}{l}\text { Geometrical textural attribute relating to } \\
\text { perception of the size and shape of particles } \\
\text { in product analyzed in mouth. }\end{array}$ \\
\hline Mouth coating & $\begin{array}{l}\text { Attribute related to the lingering of food in } \\
\text { mouth after swallowing. }\end{array}$ \\
\hline
\end{tabular}

\section{Rheological analysis}

Both rheological analyses were conducted on a rotational rheometer RheolabQC (Anton Paar $\mathrm{GmbH}$ ) with a concentric cylinder measuring geometry. Different measuring systems were used for viscosity (CC27 - bob geometry) and yield point measurement (ST-22-4V-40 - vane geometry). For each rheological analysis, an adequate measuring profile (shear rate range, measuring point duration, operation mode, etc.) for the samples needed to be determined (Malkin and Isayev, 2017). Measuring profiles for pâté products in this study were determined experimentally. Viscosity measurements and yield point measurements were repeated ten times for each sample. The rheometer was serviced and calibrated by licensed Anton Paar $\mathrm{GmbH}$. Both analyses were performed at $25{ }^{\circ} \mathrm{C}$ utilizing a Julabo $E D$ water bath coupled with the rheometer.

Viscosity is a rheological parameter defined as a measure of the material's resistance to flow and deformation (Mezger, 2019). Fish pâté viscosity was measured with the $\mathrm{CC} 27$ measuring system. Twenty grams of sample were needed for each viscosity measurement. Fish pâté viscosity was measured using shear rate from 0.1 to $100 \mathrm{~s}^{-1}$. Lower shear rates $(0.1$ $\left.\mathrm{s}^{-1}\right)$ simulate viscosity at rest, while higher shear rates $\left(100 \mathrm{~s}^{-1}\right)$ simulate viscosity during spreading.

Yield point is a rheological parameter defined as the minimum amount of force required to initiate flow (Mezger, 2019). Consumer studies have shown that an appropriate yield point is correlated with the perceived quality of spreadable products, even more so than viscosity measurement (Sun and Gunasekaran, 2009). Forty grams of sample was needed for each yield point measurement. For this research, yield point was measured using a constant shear rate of $1 \mathrm{~s}^{-1}$ for 150 seconds. To maintain a constant shear rate, the force required (shear stress) increased up until the yield point because the sample's internal structure was being progressively stretched. Yield point was determined at the peak of the graph, when the internal structure of the product has been destroyed and the force needed to maintain a constant shear rate started to rapidly decrease (Kealy, 2007).

\section{Statistical analyses}

Statistical analysis of sensory profiling and rheological data included descriptive statistics (means and standard deviations) and Student t-test for significant difference between samples. Correlation of sensory and rheological data was analyzed by Pearson coefficient (Estanqueiro et al., 2016). Level of significance was set at $p<0.05$. Statistical analyses were performed in PAST v 4.03 (Hammer et al., 2001).

\section{Results and discussion}

\section{Sensory analysis}

The descriptive sensory profiles of the samples of fish pâtés were described by experts with 13 attributes listed in Table 1.

A statistically significant difference $(p<0.01)$ between samples was perceived for appearance: color (commercial fish pâté had a lighter intensity of color) and saltiness (laboratory prototype was saltier than commercial fish pâté). Seasoning odor and flavor were almost identical, in the range of medium intensity. Intensity of fish odor was also slightly, but significantly different, with commercial fish pâté having lower intensity than laboratory prototype. Fish flavor was more intense in laboratory prototype $(p<0.05)$. The aftertaste was of medium intensity after swallowing, without any uncharacteristic notes. Saltiness was perceived as the most intense attribute of laboratory prototype (Table 2). Within the overall fish pâté attributes, texture was related to six attributes listed in Table 2.

Excluding spreadability, commercial fish pâté had significantly higher density $(\mathrm{p}<0.01)$, graininess $(\mathrm{p}<0.01)$, plasticity $(\mathrm{p}<0.05)$, and surface $(p<0.1)$ than did laboratory prototype (Fig.1). Comparing all attributes, 
density was perceived as the most intense parameter describing commercial fish pâté, while it was spreadability for laboratory prototype (Table 2).

Table 2. Overview of sensory attribute intensity between samples of fish pâté (based on two replicates) expressed as mean values and standard deviation.

\begin{tabular}{|l|l|l|}
\hline Attributes & $\begin{array}{l}\text { Commercial fish } \\
\text { pâté (Mean } \pm \text { STD) }\end{array}$ & $\begin{array}{l}\text { Laboratory prototype } \\
(\text { Mean } \pm \text { STD) }\end{array}$ \\
\hline Color*** & $49.9 \pm 0.6$ & $72.5 \pm 14.2$ \\
\hline Seasoning (odor) & $58.3 \pm 3.3$ & $64.1 \pm 18.3$ \\
\hline Fish odor** & $41.8 \pm 6.8$ & $49.5 \pm 15.7$ \\
\hline Seasonings & $88.9 \pm 2.7$ & $90.7 \pm 18.2$ \\
\hline Fish flavor* & $75.1 \pm 1.9$ & $82.4 \pm 18.1$ \\
\hline Saltiness*** & $74.7 \pm 2.3$ & $93.4 \pm 16.4$ \\
\hline Aftertaste & $82.0 \pm 31.7$ & $84.1 \pm 35.5$ \\
\hline Surface* & $98.1 \pm 7.7$ & $87.8 \pm 22.7$ \\
\hline Plasticity** & $75.6 \pm 1.9$ & $64.8 \pm 21.3$ \\
\hline Spreadability*** & $112.5 \pm 4.9$ & $123.9 \pm 6.2$ \\
\hline
\end{tabular}
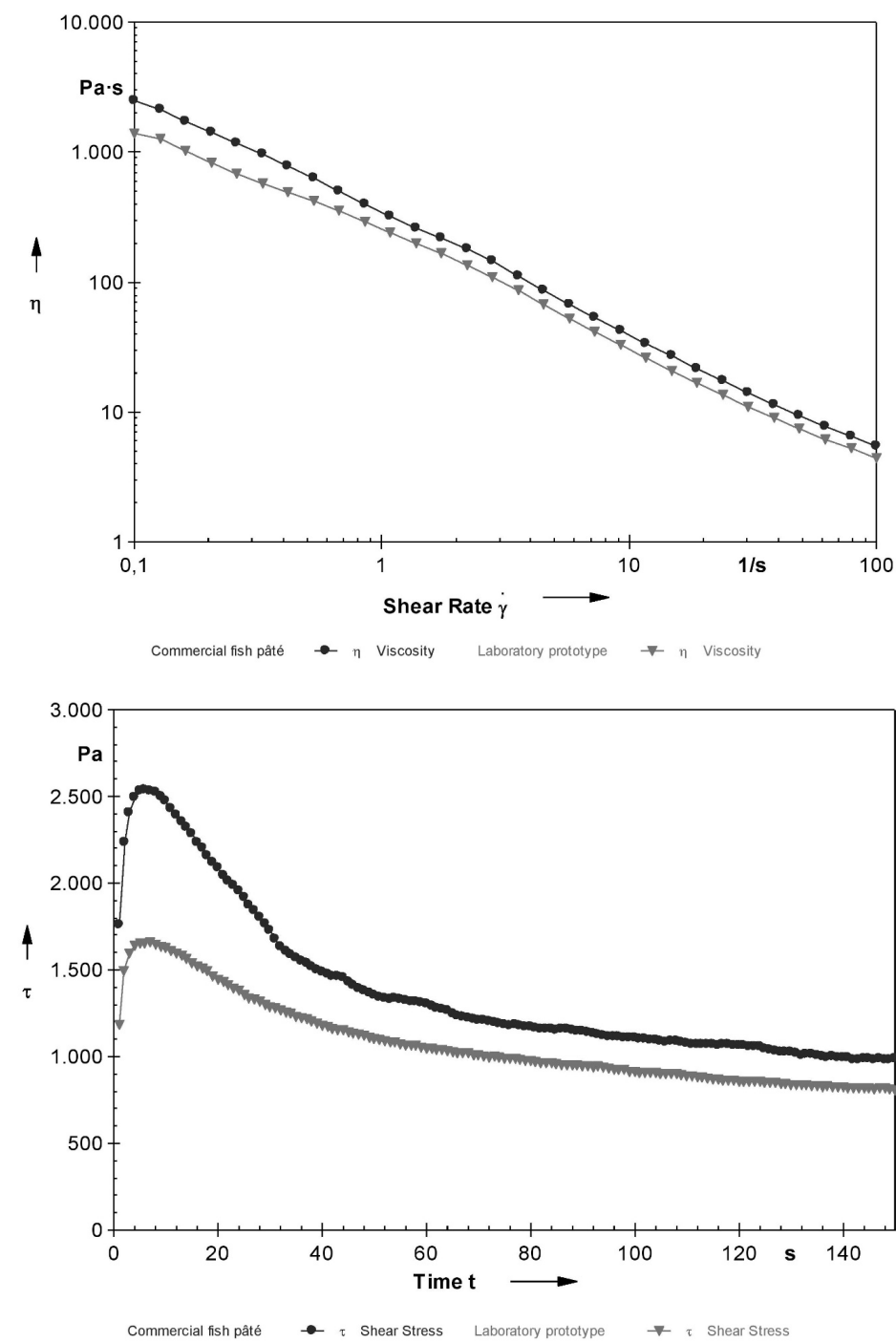

Figure 1. Viscosity curve of fish pâté samples at $25^{\circ} \mathrm{C}$.

Figure 2. Yield point measurement of fish pâté samples at $25^{\circ} \mathrm{C}$. 
Table 3. Viscosity at rest, viscosity at $100 \mathrm{~s}^{-1}$ and yield point values of fish pâté samples at $25^{\circ} \mathrm{C}$. Statistical significance considered at ***: $p \leq 0.01$.

\begin{tabular}{|c|c|c|c|}
\hline Sample & $\begin{array}{l}\text { Viscosity at } \\
\text { rest }(\mathrm{Pa} \cdot \mathrm{s}) \\
\left(25^{\circ} \mathrm{C}\right) * * *\end{array}$ & $\begin{array}{l}\text { Viscosity at } \\
100 \mathrm{~s}^{-1}(\mathrm{~Pa} \cdot \mathrm{s}) \\
\left(25^{\circ} \mathrm{C}\right) * * *\end{array}$ & $\begin{array}{l}\text { Yield point } \\
(\mathrm{Pa}) \\
\left(25^{\circ} \mathrm{C}\right) * * *\end{array}$ \\
\hline $\begin{array}{l}\text { Commercial } \\
\text { fish pâté }\end{array}$ & $2550 \pm 32.2$ & $5.53 \pm 0.31$ & $2525 \pm 55.8$ \\
\hline $\begin{array}{l}\text { Laboratory } \\
\text { prototype }\end{array}$ & $1420 \pm 31.8$ & $4.49 \pm 0.38$ & $1680 \pm 52.4$ \\
\hline
\end{tabular}

\section{Correlation of sensory and rheology results}

The results from rheological analyses were compared with texture attributes of density and spreadability evaluated by sensory analysis in order to determine correlation between these methods. Viscosity at rest indicated the density (firmness) of the texture, while viscosity at $100 \mathrm{~s}^{-1}$ and yield point related to ease of spreadability.

Commercial fish pâté had higher density according to sensory analysis and higher viscosity at rest according to rheological analysis which shows these results were in correlation. Commercial fish pâté had harder spreadability than did laboratory prototype according to sensory analysis as well as according to rheological analysis of viscosity at 100 $\mathrm{s}^{-1}$ and yield point.

Correlation was employed to assess the relationship of sensory and rheological data (Table 4). Pearson coefficient indicated that the spreadability of samples highly negatively correlated $(\mathrm{p}<0.05)$ to all three parameters of rheological data, indicating that the higher the intensity of spreadability, the lower the viscosity of the samples, which is to be expected. The opposite was true for density, also as expected, with higher sample density producing higher viscosity rates for all rheological parameters $(\mathrm{p}<0.05)$. Other texture attributes showed lower, not statistically significant correlations to instrumental rheological measurements.

The results suggest that sensory analysis is a reliable tool in evaluating the texture of this type of product supplemented with rheology analysis, as shown in previous research on different types of product categories (Matignon et al., 2016; Luckett et al., 2014; Adhikari et al., 2003; Breuil and Meullenet, 2001).

Sensory attributes are an important factor in the overall acceptability and liking of a food product. Particularly for pâté-type products, appearance and texture seem to be key attributes (Engelen and de Wijk, 2012; Siret and Issanchou, 2010). Therefore, during product development of pâte-type of products, an attribute lexicon should be generated that is correlated to objective instrumental measurements, as supported by Wendin et al., 2010.

Table 4. Correlation matrix (Pearson coefficients) of the textural and rheology values of the samples. Statistical significance considered at **: $p$ $<0.05$.

\begin{tabular}{|c|c|c|c|c|c|c|c|c|c|}
\hline & $\mathrm{S}$ & $\mathrm{P}$ & $\mathrm{Sp}$ & $\mathrm{D}$ & G & MC & YP & VR & $\begin{array}{l}\mathrm{V} \text { at } 100 \\
\mathrm{~s}^{-1}\end{array}$ \\
\hline \multicolumn{10}{|c|}{ Texture attributes (Sensory analysis) } \\
\hline Surface (S) & 1.000 & - & - & - & - & - & - & - & - \\
\hline Plasticity (P) & -0.052 & 1.000 & - & - & - & - & - & - & - \\
\hline Spreadability (Sp) & -0.289 & -0.467 & 1.000 & - & - & - & - & - & - \\
\hline Density (D) & 0.274 & 0.659 & $-0.705^{* *}$ & 1.000 & - & - & - & - & - \\
\hline Graininess $(\mathrm{G})$ & 0.233 & 0.373 & -0.433 & 0.391 & 1.000 & - & - & - & - \\
\hline Mouth coating (MC) & 0.482 & 0.060 & -0.199 & 0.281 & -0.206 & 1.000 & - & - & - \\
\hline \multicolumn{10}{|c|}{ Rheology (instrumental analysis) } \\
\hline Yield point $(\mathrm{Pa})(\mathrm{YP})$ & 0.445 & 0.511 & $-0.879 * *$ & $0.816^{* *}$ & 0.329 & 0.404 & 1.000 & - & - \\
\hline $\begin{array}{l}\text { Viscosity at rest } \\
(\mathrm{Pa} \cdot \mathbf{s})(\mathrm{VR})\end{array}$ & 0.440 & 0.524 & $-0.883 * *$ & $0.826 * *$ & 0.298 & 0.416 & 0.991 & 1.000 & - \\
\hline $\begin{array}{l}\text { Viscosity at } 100 \mathrm{~s}^{-1} \\
(\mathrm{~Pa} \cdot \mathrm{s})\left(\mathrm{V} \text { at } 100 \mathrm{~s}^{-1}\right)\end{array}$ & 0.411 & 0.503 & $-0.817 * *$ & $0.735 * *$ & 0.147 & 0.476 & 0.959 & 0.970 & 1.000 \\
\hline
\end{tabular}




\section{Conclusions}

Based on results in this study, sensory and rheological measurements of consumer's highly valued fish pâté are characterized by lower to medium flavor intensity and a firm, dense texture that is easy to spread. These characteristics are favorable with regional consumers. The internal fish pâté prototype showed some benefits in color, flavor, and seasonings, but its texture needs to be adjusted to consumer expectation, since consumers would probably tend to compare their memory with the fish pâté they are used to. Consequently, the acceptability of the organoleptic attributes of a fish pâté laboratory prototype should be tested on a representative consumer sample.
Procedure and data presented in this study could encourage food producers to utilize both methods for new product development of other pâtés/spreads/dips on an operational level. Due to the fact that processed foods have the stigma of high salt content and low nutrient density, food manufacturers are trying to reformulate the composition of products for the benefit of human health. Keeping in mind that lowering salts and fortifying with e.g. fibers and/or proteins would probably affect flavor and texture, objectively combining sensory and rheological measurements could help food developers in accelerating product development.

\section{References}

Adhikari K., Heymann H., Huff, H.E. (2003) Textural characteristics of low fat, fullfat and smoked cheeses: sensory and instrumental approaches. Food Quality and Preference, 14 211-218.

Breuil P., Meullenet J.F. (2001) A comparison of three instrumental tests for predicting sensory texture profiles of cheese. Journal of Texture Studies, 32 41-55.

Engelen L., de Wijk R.A. (2012) Oral Processing and Texture Perception In: Food oral processing: fundamentals of eating and sensory perception, John Wiley \& Sons (Ed.), Chichester, West Sussex, pp 159-176.

Estanqueiro M., Amaral M. H., Sousa Lobo J. M. (2016) Comparison between sensory and instrumental characterization of topical formulations: impact of thickening agents. International Journal of Cosmetic Science, 38(4) 389-398.

Grand View Research (2019) Pates market size, share \& trends analysis report by product type, by region, and segment forecasts, $2019-2025$. Retrieved from https://www.grandviewresearch.com/industry-analysis/pates-market/segmentation Accessed 14.11.2020.

Hammer Ø, Harper D.A.T, Ryan P.D. (2001) PAST: Paleontological statistics software package for education and data analysis. Palaeontol. Electronica. 4:9. Retrieved from http://palaeo-electronica.org/2001_1/past/issue1_01.htm Accessed 5.10.2020.

HR EN ISO ISO 8586-1 (2012) General guidance for selection, training and monitoring of assessors. International Organisation for Standardisation. Geneva, Switzerland.

HR EN ISO 11036 (1990) Texture profile. International Organisation for Standardisation. Geneva, Switzerland.

HR EN ISO 13299 (2016) General guidance for establishing a sensory profile. International Organisation for Standardisation. Geneva, Switzerland. HR EN ISO ISO 5492 (1999) Vocabulary. International Organisation for Standardisation. Geneva, Switzerland.

Kealy T. (2007) How to measure yield stress for food industries. Retrieved from http://www.rheologysolutions.com/downloads/resources/rheo362$363 \% 20-\% 20$ Food\%20-\%20Yield\%20Stress.pdf Accessed 14.5.2020.

Kesić T. (1999) Ponašanje potrošača, ADECO d.o.o. Publ., Zagreb, pp 7-12.

Lawless H.T., Heymann H. (2010) Sensory evaluation of food: principles and practices, Springer Science \& Business Media, New York, pp 57-77. Luckett C.R., Kuttappan V.A., Johnson L.G., Owens C.M., Seo H.S. (2014) Comparison of three instrumental methods for predicting sensory texture attributes of poultry deli meat. Journal of Sensory Studies, 29 171-181.

Malkin A.Y., Isayev A. (2017) Rheology concepts, methods and applications (3rd edition), ChemTec Publishing, Toronto, pp 290-304.

Matignon A., Michon C., Reichl P, Barey P., Mauduit S., Sieffermann J.M. (2016) Texture design based on chemical-physics knowledge of dairy neutral desserts: Instrumental and sensory characterizations. Food Hydrocolloids, 52 289-300.

Mezger T.G. (2019) Applied rheology (6th edition), Anton Paar GmbH, Austria, pp 31-47.

Mojet J., Köstner E.P. (2002) Texture and flavor memory in foods: An incidental learning experiment. Appetite, 38 110-117.

Nielsen T., Mihnea M., Båth K., Cunha S.C., Fereira R., Fernandes J.O., Gonçalves A., Nunes M.L., Oliveira H. (2020) New formulation for producing salmon pâté with reduced sodium content. Food and Chemical Toxicology, 143111546.

Okuskhanova E., Rebezov M., Yessimbekov Z., Tazeddinova D., Shcherbakov P., Bezhinar T., Vagapova O., Shcherbakova T., Stuart M. (2018) Rheological Properties of Low-calorie Red Deer Meat Pâté. Journal of Pharmaceutical Research International, 23 (1) 1-9.

Ranilović J., Markovina J. Žnidar K., Colić Barić I. (2009) Attitudes to healthy eating among a representative sampling of Croatian adults: A comparison with Mediterranean countries. International Journal of Food Sciences and Nutrition, 60 (S7) 11-29.

Siret F., Issanchou S. (2010) Traditional process: influence on sensory properties and on consumers' expectation and liking Application to 'pâté de campagne'. Food Quality and Preference, 11 (3) 217-228.

Sun A., Gunasekaran S. (2009) Yield stress in foods: measurements and applications. International Journal of Food Properties, 12 70-101.

Wendin K., Ekman S., Bülow M., Ekberg O., Johansson D., Rothenberg E., Stading M. (2010) Objective and quantitative definitions of modified food textures based on sensory and rheological methodology, Food \& Nutrition Research, 545134 - DOI: 10.3402/fnr.v54i0.5134. 